\title{
Os desafios na produção do conhecimento histórico sob a perspectiva do Tempo Presente
}

Enrique Serra Padrós*

Resumo. O artigo examina algumas questões referentes à produção do conhecimento histórico, relacionando-as com a abordagem da História do Tempo Presente. As reflexões sobre o Tempo Presente como campo de análise da História têm se multiplicado nos últimos anos. Elas expressam: a tentativa de delimitar esse campo de análise e de intervenção do historiador; a adequação do seu arsenal teórico-metodológico; e a elaboração de novos instrumentos que lhe permitam enfrentar eficientemente o desafio da aceleração histórica das últimas décadas. Palalvras-chave: Tempo Presente. História do Tempo Presente. Produção de conhecimento histórico.

Os historiadores sempre mostraram interesse pelos acontecimentos do seu tempo. Provavemente, as reflexões sobre o tempo presente não sejam tão novas como parecem, mas o fato é que, a partir dos anos 1980, tem-se intensificado sua problematização

*Enrique Serra Padrós é Mestre em Ciência Política pela UFRGS, Doutorando no PPG-História/UFRGS e professor de História Contemporânea no Departamento de História da UFRGS.

Anos 90, Porto Alegre, v. 11, n. 19/20, p.199-223, jan./dez. 2004 
Os desafios na produção do conhecimento histórico...

como campo de análise da história. Nas reflexões historiográficas a esse respeito, percebe-se haver uma certa confusão referente às limitações do seu campo e um questionamento relativo à sua existência e à sua validade.

Sem haver maior precisão de consenso, termos como História Contemporânea, História do Tempo Presente e História Imediata muitas vezes são utilizados de forma indiscriminada, como se fossem sinônimos, o que, evidentemente, confunde o receptor. No que tange à História Contemporânea, parece ser consensual entendê-la como a história do sistema capitalista (ou seja, da maturação e hegemonia das relações de produção e das contradições desse sistema). Entretanto, se a História Contemporânea apresenta tal traço de continuidade, também aponta elementos de ruptura. Tais elementos são suficientes para marcar a existência de subperíodos que, por sua vez, apresentariam lógicas diferenciadas. Ao subperíodo atual, bem como à sua forma de abordagem, denominamos História do Tempo Presente (HTP).

De acordo com Hobsbawm, a HTP é a história do nosso próprio tempo, do próprio tempo de vida do historiador, independente dos marcos significativos de ruptura - por exemplo, o advento da Guerra Fria e do pós-Guerra Fria (Hobsbawm, 1998, p. 244). Bernstein \& Milza, entretanto, discordam de que o tempo presente seria o presente vivido pelo próprio historiador e, mais, consideram que a delimitação de uma fronteira cronológica entre uma história do passado e uma história do presente é mutável, variável e imprecisa. No fundo, mostram receio a respeito da existência concreta de uma HTP: "não existem clivagens permitindo separar uma história do passado de uma história do presente porque não há entre elas nenhuma solução de continuidade" (Bernstein; Milza, 1999). Já para Barraclough, "[...] a História Contemporânea começa quando os problemas que são reais no mundo atual tomaram, pela primeira vez, uma forma visível [...]" (Barraclough, s.d., p. 19). Pode-se inferir que o período denominado pelo autor como História Contemporânea corresponde ao tempo presente. Quanto aos limites da HTP, Barraclough, ao afirmar que a época atual constitui-se

Anos 90, Porto Alegre, v. 11, n. 19/20, p.199-223, jan./dez. 2004 
a partir dos processos inconclusos, qualitativamente diferentes dos anteriores, discorda de Hobsbawm.

Dentro da HTP, estaria inserida a História Imediata (HI), que corresponde ao instante, ao agora já. René Rémond (1996, p. 207) diferencia a história de um instante (da instantaneidade), da história da proximidade (do tempo presente); nesta, segundo ele, há duração, há tempo cronológico. O desenvolvimento da HI está vinculado ao intenso crescimento tecnológico, nos últimos anos, dos meios de comunicação e apresenta novos desafios aos historiadores diante da dinâmica colocada ao grande público, quais sejam: o imediatismo da veiculação das informações - simultaneamente à realização do evento -; a amplitude do seu alcance - direcionado à opinião pública mundial -; e uma relação, aparentemente paradoxal, entre subinformação e superinformação (quantidade de informação em detrimento da sua qualidade), o que, geralmente, resulta na construção de um conhecimento fragmentado, assistemático e que banaliza os elementos significativos para a sua compreensão.

A HTP e a HI agem, portanto, sobre cronologias diferentes da História Contemporânea, correspondendo as duas ao tempo "muito contemporâneo". Sua natureza é muito parecida, assim como as questões que colocam (contração cronológica, tipo de fontes, especificidade dos seus objetos, etc.), e, de certa forma, os desafios que estabelecem também são, em parte, comum às duas.

\section{Problematizando o Tempo Presente}

Ao referir-se ao caso francês, Chauveau e Tétard (1999, p. 46) lembram que a HTP surgiu muito mais de uma pressão e demanda sociais do que de uma necessidade historiográfica. Sem dúvida, a conformação da "aldeia global" mediática e a banalização de "quase tudo", através do efêmero, do descartável e do mercadológico, têm atropelado, muitas vezes, os ritmos da produção e da divulgação do conhecimento, chegando, em determinadas ocasiões, a pautá-lo através da demanda de modismos, ancorados na mídia e no sucesso editorial.

Anos 90, Porto Alegre, v. 11, n. 19/20, p.199-223, jan./dez. 2004 
Os desafios na produção do conhecimento histórico...

Diante desse quadro, o grande desafio do conhecimento científico (portanto, também da história) consiste em não se deixar pautar pelo consumismo da lógica do mercado e intervir no sentido de dar inteligibilidade à dinâmica de uma sociedade voraz, marcada por uma aceleração histórica inédita, sem que isso seja motivado por modismos ou afins. Nesses termos, a HTP e a HI expressam uma possibilidade de se constituir um delimitador de novos campos de análise e intervenção, adequando-se o arsenal teórico-metodológico da ciência histórica e elaborando-se, com a contribuição de outras áreas do conhecimento, novos instrumentos que permitam enfrentarse eficientemente tamanho desafio.

Visando facilitar a exposição e torná-la mais pontual, são apresentadas, a seguir, algumas questões centrais na atual discussão sobre as possibilidades de a HTP configurar-se como uma área específica de intervenção dos historiadores contemplando os rigores científicos e acadêmicos pertinentes.

\section{A ciência histórica e o Tempo Presente}

A partir do texto de Braunstein (1979, $1^{\circ}$ cap.), podem-se arrolar algumas das características da prática científica. Por um lado, há o fato de a ciência não se basear na aparência dos fenômenos, mas na sua essência - o que precisa ser descortinado através de instrumental metodológico adequado. Por outro, ela se constitui a partir de um trabalho de produção de conceitos e do enfrentamento das afirmações baseadas em experiências sensoriais, em percepções externas e aparentes dos fenômenos e em convicções espontâneas, ou seja, no senso comum. Em relação a essa aparência, a ciência pode partir dela, mas o seu objetivo principal é desvelar-lhe o movimento real, quer dizer, o conhecimento do senso comum ou da ideologia (conhecimentos pré-científicos de natureza sensorial, da percepção, da emoção). O objetivo do conhecimento científico é conferir a racionalidade e a veracidade, até os limites do possível (considerando a impossibilidade de uma verdade absoluta), de todo e qualquer fenômeno. Detectando suas regularidades, analisando

Anos 90, Porto Alegre, v. 11, n. 19/20, p.199-223, jan./dez. 2004 
sua dinâmica e definindo, a partir de mecanismos de verificação, a concretude da sua especificidade, é possível estabelecer conceitos que expressem seu real sentido.

Particularmente, em relação ao conhecimento histórico, há dois elementos constitutivos centrais. Primeiro, a perspectiva de processo histórico, de uma história total, em que as diversas instâncias articulam-se, interconectam-se, formando uma rede de relações cuja lógica deve estar presente para o historiador. Segundo, um compromisso radical com a verdade - sobretudo em tempos de negacionismo -, com o real (a verdade e o real mais próximos possível do fato concretamente acontecido), assim como com a produção do conhecimento científico acumulado, pois o trabalho do historiador não pode abrir mão da dimensão científica (o método crítico com seus processos testados e seus instrumentos). A operação histórica ocorre mediante a reunião, a identificação e a análise das fontes disponíveis, estabelecendo conexões e construindo um discurso, atribuindo-lhes coerência e significado. O importante é decifrar os componentes do passado, seu encadeamento, sua hierarquização e sua participação no conjunto do esquema interpretativo. Trata-se, portanto, de uma história que problematiza, que reconhece as interconexões existentes e que utiliza os instrumentos teórico-metodológicos como ferramentas para compreender o passado iluminado desde as indagações do presente. Diante disso, é necessário lembrar sempre que, em primeiro lugar, a história do presente é, antes de tudo, história. Independente das suas especificidades, objetivos, métodos e fontes, os desafios da história do presente não são essencialmente diferentes dos da história do período anterior (Bernstein; Milza, 1999, p. 127).

As dificuldades encontradas na construção da HTP devem ser encaradas desde a perspectiva de que o fundamental é fornecer uma base explicativa que, mesmo sendo provisória, seja plausível. Desse modo, responde-se, legitimamente, a uma primeira demanda sobre o assunto em questão. Para tanto, deve-se ressaltar o papel que cumpre a utilização de uma perspectiva global e lógica da história (processo histórico). Isso é fundamental, pois é a partir de uma base

Anos 90, Porto Alegre, v. 11, n. 19/20, p.199-223, jan./dez. 2004 
Os desafios na produção do conhecimento histórico...

analítica que se pode apreender a história como processo e não como fragmentação desarticulada. De forma muito clara, Chesneaux (1984, p. 202) expõe a grande contribuição da História Imediata (aqui ampliada para o tempo presente): "a função da História Imediata deve ter como objetivo, ligar o presente aberto, com todas as suas possibilidades, com o passado mais recente". A natureza e a diversidade das suas fontes, assim como a amplitude da sua documentação, permitem, ao historiador, realizar os cruzamentos e as verificações correspondentes para estabelecer suas conclusões. Ainda que provisórias, tais explicações plausíveis são uma grande contribuição ao cenário desordenado de acontecimentos do tempo presente. Mesmo com todas as carências evidentes, uma primeira sistematização desse emaranhado de acontecimentos e de informações pode constituir um ponto de partida mais qualificado para futuras análises, não só de cunho histórico, o que configura outra função da HTP.

Em síntese, a originalidade da abordagem do presente está situada no fato de poder captar a atualidade, a novidade, a irrupção e a emergência de tendências, assim como as possibilidades de estabelecer as conexões - as "pontes" - que a interligam com o passado (evidenciando a vigência da perspectiva processual da história). Por outro lado, não há diferença concreta alguma quanto às operações básicas que realiza o historiador que trabalha com períodos mais distantes. Nesse sentido, o tempo presente exige, mediante pressupostos teóricos, o dimensionamento, a hierarquização e a contextualização dos eventos, assim como sua inserção no processo histórico e sua relação com ele. Apesar de legitimar a especificidade do tempo presente, Jacques Le Goff (1999, p. 102) aponta que a natureza científica da apreensão desse tempo estará garantida se os historiadores do imediato (aparentemente ele utiliza HI e HTP como sinônimos) trabalharem metodologicamente considerando as seguintes operações: analisar o acontecimento com profundidade histórica pertinente; trabalhar as fontes com o rigor crítico e os métodos adequados; e explicar os fatos, hierarquizá-los e integrá-los numa longa duração.

Anos 90, Porto Alegre, v. 11, n. 19/20, p.199-223, jan./dez. 2004 
Decorre dessas colocações a necessidade de uma abordagem teórica que seja macroexplicativa (abrangendo e inter-relacionando as variadas esferas), processual (fundamentada no passado histórico), estrutural (construindo explicações mais consistentes assentadas nas regularidades para, assim, identificar as rupturas), global (dimensão essencial do tempo presente em função da intrínseca associação entre as diferentes realidades) e dialética. Se os trabalhos sobre o tempo presente não tiverem esse cuidado teórico-metodológico, os resultados obtidos dificilmente deixarão de ser meramente descritivos, fragmentados e fechados numa lógica interna que pode vir a ser perigosa. Se assim for, é melhor deixar esse trabalho para os jornalistas.

\section{As fontes do Tempo Presente à luz do rigor científico}

Uma das grandes dificuldades colocadas para o estudo da HTP é a abundância e a variedade de fontes primárias existentes, a ponto de o historiador não ter condições físicas e tempo disponível para trabalhá-las. Mesmo assim, esse estudo é visto como sendo um grande privilégio, já que viabiliza a possibilidade de se recorrer a múltiplas formas de documentos escritos, à investigação das fontes orais, ao testemunho direto, às pesquisas de opinião, aos recursos iconográficos, etc. O trabalho com esses novos materiais implica, muitas vezes, a necessidade de cooperação com as demais ciências, em função do grau de especialização exigido e pela singularidade de alguns instrumentos de análise.

A familiaridade do historiador com uma opção temática decorrente da sua própria experiência de vida facilita-lhe, em tese, o diálogo com as fontes identificadas. Entretanto, sob uma perspectiva ainda muito calcada no velho positivismo, críticos apontam como um problema a existência de limitações importantes quanto ao acesso público à documentação escrita fundamental, seja em função da falta de sistematização, seja pelas restrições impostas pelas administrações governamentais (o problema concreto da desclassificação de documentos oficiais). Isso conformaria, segundo

Anos 90, Porto Alegre, v. 11, n. 19/20, p.199-223, jan./dez. 2004 
Os desafios na produção do conhecimento histórico...

tais críticos, uma situação de história sem arquivo, o que inviabilizaria a formulação de uma análise histórica do tempo presente diante da impossibilidade de se efetuar um levantamento exaustivo das fontes tradicionais. Evidentemente que esse tipo de crítica não se sustenta mais diante do quadro significativo de materiais que podem ser potencialmente transformados em fontes de pesquisa.

Metodologicamente, um historiador está instrumentalizado para enfrentar as fontes do tempo presente, mesmo considerando a já citada dificuldade de acúmulo dessas fontes e sua natureza diversa. É exeqüível, inclusive, que um historiador embrenhe-se com sucesso no campo de análise de outras ciências humanas, pois, com o manejo da cronologia e da análise crítica dos documentos, ele pode, trabalhando numa perspectiva de história total, estabelecer conexões de longo alcance. $\mathrm{O}$ reconhecimento de novos materiais com o estatuto de fontes de pesquisa evidentemente tem despertado o interesse, pelos avanços metodológicos relacionados às suas formas específicas de análise. $\mathrm{O}$ estudo do presente exige o permanente aperfeiçoamento de procedimentos de coleta de dados originais, da apreensão de novas técnicas de classificação e de métodos de análise adequados a esses novos materiais.

A existência (sobrevivência) de testemunhas, verdadeiros arquivos vivos, é uma das particularidades mais valiosas do tempo presente. Não se trata de usá-las como fonte exclusiva, mas de dar a palavra aos que foram protagonistas da história, ou seja, temos uma "História com Testemunhas", o que é diferente da "História Oral", na medida em que aquela propõe um "vaivém" (diálogo/interação) entre a produção do historiador e o protagonista do acontecimento (a testemunha). Efetivamente, neste campo de trabalho, a testemunha passa a ser um interlocutor do pesquisador, podendo interferir em momentos diferentes do trabalho, trocando informações e aferindo o conhecimento na fase da coleta de dados, da elaboração, da sistematização e até da publicitação dos resultados parciais ou finais. Portanto, constitui-se em uma fonte interativa que afere e interage, enquanto protagonista, com a leitura interpretativa resultante da análise do factual.

Anos 90, Porto Alegre, v. 11, n. 19/20, p.199-223, jan./dez. 2004 
Entretanto, se o tempo presente apresenta uma diversidade de fontes inéditas, isso não significa que, em relação a estas, existam critérios diferenciados daqueles correspondentes a outros campos de análise da história. Nesse sentido, a HTP não inventou nada de novo, não se eximindo do rigor metodológico com que deve trabalhar o historiador. Apesar de uma certa "pirotecnia" quanto às novas fontes, o fundamental ainda é a reflexão sobre elas. Logo, continuam sendo primordiais as análises interna e externa do documento, do depoimento, assim como a obrigatoriedade de o historiador cruzar as diversas fontes de que dispõe (nas perspectivas da complementação, da comparação e da verificação).

Por fim, deve-se realçar que, se as fontes constituem, concretamente, os registros através dos quais se organizam e analisam os acontecimentos (matéria-prima do conhecimento histórico), os recursos da mídia eletrônica, da informática, da Internet, dos registros cinematográficos e de tantas outras novas "fontes" contribuem, também, para construir a inteligibilidade do tempo presente, tanto quanto para outros períodos o fazem as fontes pertinentes. Em resumo, é importante terem-se registros abundantes, novos, atrativos e instigantes. O campo do tempo presente os tem; entretanto, o fundamental são as perguntas, as hipóteses, as relações, os métodos. Até porque, com esses instrumentos de análise, as fontes que resistem à verificação do seu potencial tornam-se muito mais ricas do que parecem à primeira vista.

\section{O inconcluso e o provisório no Tempo Presente}

Um dos maiores desafios colocados à HTP é o de problematizar, analisar, caracterizar e avaliar uma história cujo termo não se conhece, ou seja, uma história inconclusa. Quando Hobsbawm define o tempo presente como o "nosso próprio tempo" (1998, p. 244), aponta para essa "história em aberto", que dificulta uma percepção de mudança ou permanência. Contudo, o "fato", quando trabalhado numa abordagem crítico-científica de históriaprocesso, não aparece desconexo ou deslocado da realidade do

Anos 90, Porto Alegre, v. 11, n. 19/20, p.199-223, jan./dez. 2004 
Os desafios na produção do conhecimento histórico...

processo histórico que lhe dá sentido. Para que as análises do presente, mesmo parciais e provisórias, não se restrinjam às interpretações desconexas, fragmentadas, desarticuladas e superficiais da "cena contemporânea", deve-se "[...] esclarecer as mudanças básicas de estrutura que deram forma ao mundo moderno. Essas mudanças são fundamentais porque fixam o esqueleto ou armação em torno da qual a ação política se enquadra e desenvolve" (Barraclough, s.d., p. 16). Dessa forma, o historiador deve preocupar-se em "[...] descrever as estruturas cujas transformações dão conta da emergência factual de fenômenos cuja gênese se situa sempre a médio e longo prazo" (Bernstein; Milza, 1999, p. 127).

A inconclusividade dos processos analisados constitui um outro problema característico do tempo presente. Em função da insciência do desfecho dos acontecimentos e considerando que os fatos do presente não sofreram a necessária "decantação", o historiador pode incorrer no erro de considerar como definitivo algo provisório ou sobrevalorizar eventos que posteriormente poderão ser considerados irrelevantes. Contudo, é importante apontar que o desconhecimento do devir também concede maior liberdade para as mais diversas elucubrações, transformando a história num verdadeiro campo de possibilidades. A inconclusividade permite, também, considerar-se um maior número de hipóteses, as quais, por sua vez, apontam para uma diversidade de cenários possíveis, sujeitos a rápido descarte em uma análise já dirigida a posteriori. O que pode ser visto, em um primeiro momento, como uma dificuldade a mais (desconhecimento do desfecho dos processos) permite, ao contrário, trabalhar-se com linhas de abordagem e cenários futuros em aberto. De fato, tal possibilidade pode evitar que ocorra o que às vezes acontece quando se conhece o desfecho de uma disputa (como, por exemplo, subestimar o vigor do vencido, deixar de levantar nexos, direcionar leituras e análises segundo o resultado dos acontecimentos). Talvez seja melhor considerar que as transformações em curso permitem, ao analista, adotar uma perspectiva de maior independência em relação ao desenlace delas. 
Nesse sentido, é fundamental saber identificar e separar os elementos considerados essenciais dos superficiais. As análises parciais devem contemplar a possibilidade de que, por ser uma história inconclusa, em movimento, novas ponderações possam dar correção de rumo. Aliás, por mais óbvio que possa parecer, é importante lembrar que a possibilidade de novos questionamentos perpassam todo o espectro da história (seja passada ou presente). Logo, o caráter de inconclusividade não é um critério que inviabilize o trabalho do historiador, até porque, numa perspectiva de história processual, sempre há uma história inconclusa que exige realçar linhas tendenciais, de continuidade e de ruptura. Isso não significa negar que trabalhar com uma história em aberto dificulta uma percepção mais concreta da profundidade real das mudanças e das permanências. Mesmo assim, diante de tal desafio e assumindo toda cautela necessária, as reflexões acerca do imediato, ainda que sejam provisórias, sendo cientificamente plausíveis, podem constituir uma contribuição qualificada na atual torrente de (des)informação. Assim, o historiador do tempo presente, preocupado com a cientificidade da elaboração das suas explicações, realiza processos de identificação, classificação, montagem e racionalização, bem como os cruzamentos e verificações que lhe permitem a diversidade de suas fontes e a amplitude da sua documentação.

\section{História e objetividade}

A procura de objetividade na história implica a permanência de um componente subjetivo que é imanente a toda produção do conhecimento científico e impõe a vigilância do componente subjetivo, o que pode ser feito através dos seguintes instrumentos: a utilização de recursos metodológicos e conceituais adequados; o respeito às evidências concretas; a elaboração de hipóteses pertinentes; o uso de um referencial teórico que capte os movimentos internos do fenômeno; e o estabelecimento de relações com outros nexos do real. Tudo isso emoldurado numa rigorosa postura ética do historiador, submetendo seus interesses aos cânones da ciência e da verdade.

Anos 90, Porto Alegre, v. 11, n. 19/20, p.199-223, jan./dez. 2004 
Os desafios na produção do conhecimento histórico...

Uma história objetiva não anula o sujeito, mas estabelece com ele uma relação de equilíbrio através dos mecanismos de controle e aferição mencionados, que garantem a legitimidade do que seja produzido como conhecimento (científico). A forma legítima de um historiador garantir credibilidade ao emitir opiniões sobre uma base de dados objetivos é fazê-lo através de um trabalho permanente de revisão, verificação e acumulação de conhecimentos parciais. É dessa forma que ele pode contribuir para a consolidação da objetividade histórica.

Nesse sentido, Carlos Pereyra (1984, p. 11), em um texto cujo título já traz uma questão central da discussão epistemológica da história, História ¿para qué?, propõe a problematização da função ou utilidade do conhecimento histórico. A questão por ele colocada é a da legitimidade da história: por um lado, se o saber histórico comprova sua legitimidade teórica; por outro, se tal conhecimento resulta útil para além do plano científico.

O conhecimento histórico percebido como "guia para a ação" tem largo registro na história. Na prática, todo discurso histórico pode ser objeto de instrumentalizações política, social, cultural, etc. Porém, isso não valida equivalentemente as qualidades teóricas do discurso histórico (sua legitimidade) e sua utilidade ideológicopolítica (função social), pois esta última não possui uma magnitude diretamente proporcional à validade teórica.

Não se pode confundir o objetivo científico da pesquisa com a instrumentalização dos seus resultados motivada por critérios político-ideológicos, até porque o produto do trabalho do historiador, ao ser socializado, escapa do seu controle. "Quer gostem disso ou não, os historiadores profissionais produzem a matériaprima para o uso ou abuso dos não-profissionais" (Hobsbawm, 1998, p. 285). Evidentemente, também não se pode condicionar a pesquisa em função do tipo de utilização que após se poderá fazer dos seus resultados; se assim for, não haverá mais pesquisa. Le Goff (1998, p. 32) coincide com a tese de Pereyra ao explicitar que não se deve confundir história humana (função social) com história científica. A norma da veracidade é uma norma do conhecimento histórico

Anos 90, Porto Alegre, v. 11, n. 19/20, p.199-223, jan./dez. 2004 
que se posiciona contra a função social das recordações históricas e do senso comum, enfatizando os procedimentos científicos em que cada declaração é confirmada pela veracidade das fontes.

Por último, vale a pena lembrar uma outra questão colocada por Pereyra (1984, p. 11) e que consiste no fato de alguns historiadores assumirem uma atitude de querer julgar o passado em vez de tentar explicá-lo. Provavelmente, tal fato é suscitado, também, por motivações de cunho político-ideológico; aliás, dependendo do objeto, tais motivações podem ser terrivelmente sedutoras. Entretanto, essa inversão entre o porquê e o quem é o culpado confunde o objeto e o objetivo da ciência história. Levantar dados, relacionar fatos, explicar processos e avaliar os resultados dessas operações mentais fundamentam uma consistente contribuição da história à produção de conhecimento científico e, conseqüentemente, à sociedade; fora disso, corresponde a outras instâncias dessa última, desempenhar certas tarefas e assumir determinadas responsabilidades. De qualquer forma, não é demais lembrar que, assim como ocorre no interior da sociedade, a história também é perpassada por disputas diversas, tanto em função da complexidade dos interesses em jogo, quanto pela importância que possui na definição de uma eficiente função social de controle e de legitimação do sistema vigente.

\section{A relação objeto-sujeito na proximidade temporal}

A questão das proximidades temporal e material do autor em relação ao objeto estudado tem sido um tema recorrente nas críticas realizadas à possibilidade de atuação do historiador no tempo presente. Neste sentido, argumenta-se que a inserção do historiador e do seu objeto de pesquisa no mesmo plano histórico determinam o envolvimento do sujeito com o seu entorno. Deve-se reconhecer, a bem da verdade, ser esse um questionamento extremamente pertinente. A imersão do historiador e do seu objeto de pesquisa no mesmo processo histórico pode inviabilizar maior clareza no que diz respeito à distinção de tendências dentro do período 
Os desafios na produção do conhecimento histórico...

(continuidade, ruptura, início, etc.), assim como induzir a conclusões que podem ser falsas ou imprecisas. A falta de um maior distanciamento temporal entre o sujeito que analisa e o objeto de estudo pode levar a considerações inadequadas, confundindo o que seja transitório com o que seja permanente e vice-versa.

O historiador não pode evitar fazer parte do seu entorno histórico. Ele está inserido, isso é inegável. Nesse caso, a alternativa é a de que o historiador objetive alcançar o máximo de isenção, não se deixando levar pelos seus desejos nem pela aparência superficial das coisas. Além disso, a ausência de distanciamento cronológico pode ser considerada como uma potencialidade do tempo presente; sem a pretensa objetividade positivista, o historiador, ao ter que analisar os acontecimentos na simultaneidade da sua manifestação, fica muito mais exposto e é "obrigado" a esclarecer sua orientação teórico-metodológica e até mesmo política.

Logo, a ausência de distanciamento entre o sujeito e o objeto consiste-se em uma peculiaridade da HTP. Considerando que o observador do tempo presente é um contemporâneo do acontecimento, não há como negar a possibilidade da subjetividade. Isso exige que a pesquisa resultante de um estudo com essa abordagem deva estar predeterminada por uma permanente ação de objetivação (Paillard, 1993). Assim, para fugir da armadilha da subjetividade, é fundamental que o historiador esteja munido de uma sólida e rigorosa base teórico-metodológica que lhe possibilite a maior isenção possível, deixando de lado as aparências superficiais dos fatos e seus interesses.

O aumento da carga subjetiva não inviabiliza a avaliação crítica do fato recente, já que existem instrumentos que permitem promoverem-se procedimentos que submetam a subjetividade do pesquisador na busca de um conhecimento histórico científico, objetivo e, portanto, legítimo. A história, enquanto ciência, visa alcançar a verdade, opondo-se, entre outros, ao senso comum criado pela mídia. Além disso, há diferença entre o distanciamento crítico e aquele temporal, entre a isenção e a pretensa neutralidade. ${ }^{1}$

Anos 90, Porto Alegre, v. 11, n. 19/20, p.199-223, jan./dez. 2004 
Nesse sentido, Lacouture (1998, p. 230) afirma que “[...] o historiador do presente permanece honesto ao manifestar suas opções. [...] o imediatista encontra a salvação no aclaramento de

suas orientações. É se manifestando que ele se neutraliza, ou abre para si as portas da eqüidade." Portanto, explicitar posições honestamente confere, ao historiador, a isenção necessária para a realização de uma análise objetiva e científica. Além disso, a subjetividade não é um desafio exclusivo do historiador do presente nem um fato singular da contemporaneidade.

Finalmente, cabe ressaltar ser insustentável a afirmação de que a existência de um maior distanciamento cronológico entre sujeito e objeto garante isenção no produto final do trabalho da pesquisa. Se assim fosse, a HTP e a HI acabariam completamente contaminadas por julgamentos morais, político-partidários e por outros prejuízos resultantes da falta de neutralidade do analista. Em contrapartida, dentro dessa mesma lógica, nos estudos sobre os povos da antiga Mesopotâmia, tal perigo nunca ocorreria. Isso quer dizer que o discurso da defesa do distanciamento temporal não passa de um exercício de retórica; ele, per si, não diminui a subjetividade, da mesma forma como a objetividade pura e a neutralidade (condição impossível de ser alcançada por qualquer cientista). Portanto, a hipótese da falta de recuo temporal como comprometedor da objetividade da pesquisa não se sustenta: "é o próprio historiador, desempacotando sua caixa de instrumentos e experimentando suas hipóteses de trabalho, que cria sempre, em todos os lugares e por todo o tempo, o famoso recuo" (Rioux, 1999, p. 146).

\section{O problema do engajamento}

O engajamento constitui uma questão que é, sem dúvida, uma das mais delicadas sob a perspectiva da história do tempo presente. O conhecimento científico sobre as estruturas de dominação social e sobre como elas envolvem cada indivíduo não pode ser ocultado nem pode ser considerado neutro, uma vez que contribui para o desmascaramento da opressão social. Esse conhecimento, se por si

Anos 90, Porto Alegre, v. 11, n. 19/20, p.199-223, jan./dez. 2004 
Os desafios na produção do conhecimento histórico...

só não transforma a realidade, orienta, porém, as práticas de transformações das estruturas, ou seja, sem tal conhecimento, é impossível pensar-se nas transformações de fundo. Diante disso, os setores dominantes de uma dada sociedade não ficam imóveis quando ameaçados. Logo, não surpreende que seus intelectuais orgânicos neguem, por exemplo, o conteúdo científico do materialismo histórico e da psicanálise. Por que não deveriam ocultar as críticas e conteúdos? Por que não deveriam sustentar a idéia de que a ciência se constitui por acumulação gradual e de modo contínuo a partir da experiência sensorial?

Eric Hobsbawm (1998, p. 139), ao abordar a questão do engajamento, aponta para duas possibilidades. De um lado, o engajamento nos fatos, que ele denomina de "engajamento objetivo"; por outro lado, o engajamento das pessoas, o "engajamento subjetivo". Tanto em um caso quanto no outro, o autor indica a existência de nuanças nos espectros respectivos. No extremo do primeiro caso, reconhece-se, corretamente, a impossibilidade de uma ciência ser totalmente objetiva e isenta de juízos de valor, o que não significa dizer, entretanto, que a ciência seja engajada por si só. Hobsbawm discorda desse entendimento, lembrando que o engajamento na ciência ocorre na escolha e na combinação dos fatos verificados e não no seu questionamento, pois, ao serem parte do conhecimento científico, esses fatos são inquestionáveis. No extremo oposto, defende-se que tudo na ciência deva estar subordinado aos ditames da função político-ideológica; contudo a lembrança da Grande Enciclopédia Soviética mostra os absurdos cometidos na produção do conhecimento histórico em nome de uma perspectiva oficial. Por último, Hobsbawm, ao defender abertamente o engajamento legítimo do historiador na ciência, reafirma que isso não significa descomprometimento social dos intelectuais. Exemplificando com os estudos sobre o movimento operário britânico (que, até o pós-Segunda Guerra, só eram produzidos por intelectuais engajados), Hobsbawm (1998, p. 148) conclui que "Os intelectuais engajados podem ser os únicos dispostos a investigar problemas ou assuntos que (por razões ideológicas ou outras) o resto

Anos 90, Porto Alegre, v. 11, n. 19/20, p.199-223, jan./dez. 2004 
da comunidade intelectual não consegue considerar.". De qualquer forma, a realidade não é transparente. Ela exige ser decodificada, o que, por sua vez, produz reações quando fatores de controle e exploração vêm à tona. Grupos sociais interessados em manter o statu quo defendem um conhecimento instrumentalizado que reproduza as aparências enquanto reagem contra a difusão de qualquer novo conhecimento (Braunstein, 1979, cap. 1).

$\mathrm{Na}$ perspectiva dos limites entre engajamento e objetividade, arrolamos duas situações limites do tempo presente. A primeira relaciona-se com o atual debate sobre o negacionismo neonazista, no qual Vidal-Naquet (1994) assume uma forte posição contra essa forma de falsificação do Holocausto e da história do III Reich. Primeiramente, o autor caracteriza os grupos revisionistas como "assassinos da memória". Depois, denuncia-os como "caso limite" na medida em que visam "apagar" a história. De forma enfática, mostra com que armas concretas deve colocar-se o historiador diante dos "assassinos da memória" e dos defensores da mentira:

[...] não me proponho responder a essa acusação global situando-me no terreno da afetividade. Aqui não se trata de sentimentos senão da verdade. Esta palavra, que antes pesava, hoje tem uma tendência a dissolverse. Esta é uma das imposturas do nosso século, sumamente rico neste terreno (Vidal-Naquet, 1994, p. 14).

Esgrime, então, o argumento mais sólido e mais radical para enfrentar os detratores negacionistas:

Que fique entendido, de uma vez por todas, que não respondo aos acusadores, que não dialogo com eles sob nenhum aspecto. Um diálogo entre dois homens, embora sejam adversários, supõe um terreno comum, um comum respeito - no encontro - pela verdade. Mas esse terreno não existe com os revisionistas (Idem).

Anos 90, Porto Alegre, v. 11, n. 19/20, p.199-223, jan./dez. 2004 
Os desafios na produção do conhecimento histórico...

Se a verdade absoluta é inalcançável, poucos fatos, entretanto, são tão inquestionáveis quanto tudo aquilo que se insere no holocausto, fartamente documentado, testemunhado e lembrado. A veemência do posicionamento de Vidal-Naquet, fortemente engajado contra o esquecimento, não se distancia em nenhum momento de justificativas pautadas pelo conhecimento científico (histórico). Essas últimas permitem-lhe desconsiderar os negacionistas como interlocutores a respeito da revisão histórica da Segunda Guerra Mundial, ou seja, Vidal-Naquet não aceita debater com quem baseia seus argumentos em pressupostos históricos reconhecidamente falsos (o que é constatado através da volumosa produção histórica existente), fora da lógica científica e mediante uma memória reconstruída a partir de premissas irreais.

Em última instância, a sonegação da informação e da experiência assim como a imposição do esquecimento são mecanismos necessários para se consolidar o anestesiamento geral e a desresponsabilização histórica. Tais mecanismos contribuem para a implantação de uma memória "reciclada" que interessa ao poder dominante e que, evidentemente, se afasta ainda mais do (passado histórico) real. Diante disso, o engajamento de Vidal-Naquet não implica absolutizar a função social da história em detrimento da sua função científica; pelo contrário, sua fala "raivosa" e sua convicção no paradigma científico reafirmam os pressupostos da racionalidade. Ademais, se no âmbito do discurso, o autor pode parecer "panfletário", um pouco na linha da indignação de Paulo Freire (1996), entretanto, assim como este, não se deixa cegar pela raiva justificada -, propondo o debate no plano do conhecimento científico. Aliás, é através da valorização dessa condição que VidalNaquet denuncia e desqualifica a ausência completa de cientificidade nas posições negacionistas.

Um outro exemplo de engajamento, também em situação limite, relaciona-se ao complexo e traumático processo de recuperação da memória e da história dos desaparecidos na Argentina. Trata-se do caso de três professoras (Dussel; Finocchio; Gojman, 1997, p. IX), que, munindo-se de toda cautela e conscientes

Anos 90, Porto Alegre, v. 11, n. 19/20, p.199-223, jan./dez. 2004 


\section{Enrique Serra Padrós}

das limitações concretas que seriam enfrentadas, ${ }^{2}$ se propuseram trabalhar com tal temática e escreveram um livro destinado à rede escolar daquele país:

[...] tivemos [...] uma vontade imensa de juntar nossas idéias e saberes para aportar ao que consideramos que continua sendo uma conta pendente na educação e na sociedade argentina: a construção de uma memória sobre a história recente que tenha como interlocutores às novas gerações. [...] Mas com medo de produzir versões fragmentadas, de assumir-mos a verdade absoluta num debate que continua aberto, em suma, de esquecer uma parte importante da história.

Portanto, sem ter muito claro o perfil do que poderia ser um livro que resgatasse o tempo presente argentino, as autoras, desde a problemática do terror de Estado e da luta pelos direitos humanos e pela memória histórica, precisaram abordar a questão após um rigoroso exame do método científico:

[...] uma maneira de abordar este problema consistiu assumirmos marcos de referência explicativos e de informação que ajudaram a dar conta das múltiplas dimensões que se condensam nessa questão. Para nós, ler o Nunca Mais [relatório produzido pela Comisión Nacional de los Desaparecidos - CONADEP] sem referirmo-nos à história política e social de nosso país, sem discutir política e filosoficamente a questão da violência e a construção de uma memória, pode resultar numa experiência semelhante à de olhar um filme de terror, onde a única coisa que queremos é que termine logo para abandoná-lo no canto mais afastado das lembranças. É inquestionável que não se pode evitar que os leitores [...] se enfrentem com a dor e com a impotência diante da magnitude e características da repressão que os testemunhos revelam e [...] também é desejável que possam 
Os desafios na produção do conhecimento histórico...

trabalhar-se como argumentos racionais a favor da tolerância e da construção de outra cultura política (1997, p. IX).

Diante de tudo o que foi colocado até aqui em relação ao engajamento, é importante ressaltar alguns aspectos. Primeiro, a necessidade de se refletir sobre questões complexas, assumindo-se atitude de engajamento e de compromisso contra os processos de esquecimento em marcha. O segundo, partindo-se de uma perspectiva de análise abrangente, explicativa e total, a exigência de propor-se uma leitura contextualizada de obras como o Nunca Mais e de eventos como o Holocausto, articulando-se todas as instâncias possíveis no conjunto da sociedade. Finalmente, a pertinência de se esperar uma certa postura pedagógica, no sentido de se aprender com os acontecimentos, assim como pretender fornecer subsídios para mudar o que exista (possibilidade de função social). Neste caso, como naquele apontado por Vidal-Naquet, parece claro haver uma dupla validade e justaposição das funções teórica e social da história. Nessas situações concretas, cabe bem a posição de Josep Fontana (1998, p. 37), quando destaca que

[...] nem os métodos nem a teoria são objetivo final do nosso trabalho, são apenas ferramentas para tratar de entender melhor o mundo em que vivemos e ajudar os outros a entendê-lo, a fim de contribuir para melhorá-lo, o que faz falta.

\section{Conclusão: o Tempo Presente e a ética do historiador}

Pesquisar o tempo presente é função do especialista e responsabilidade social do historiador, que deve estar atento a tudo, que precisa posicionar-se diante dos mitos, dos preconceitos, das deformações da consciência coletiva e da memória. Ele também está

Anos 90, Porto Alegre, v. 11, n. 19/20, p.199-223, jan./dez. 2004 
intimidado a esclarecer o caso, a fornecer um fio condutor por onde passe o crivo da função crítica, da função cívica e da função ética. Ele mesmo contribui para a construção dessa consciência e memória.

Analisando as situações limite colocadas pelas discussões do nazismo, Bédárida (1998) instiga o historiador a assumir uma posição que vá além da sua atuação no campo científico, intervindo na esfera pública e pronunciando-se sobre os riscos implícitos para a sociedade no amplo processo negacionista conduzido pelos falsificadores da história. É do ônus do expert-o historiador especialista -, fortemente legitimado pela opinião pública, oferecer opiniões elucidativas. "A palavra de expert do historiador, observadas as regras do ofício e respondendo aos questionamentos do Tempo Presente, é perfeitamente legítima, restituindo à história sua densidade significante" (ibid., p. 46).

Algumas idéias de Paulo Freire (1996) podem contribuir ao debate, mesmo não sendo ele um historiador. Em relação à questão ética, dizia o autor, os educadores deviam assumir uma "ética universal do ser humano" inseparável da sua prática educativa. Dentro dela, há lugar para condenar o discurso neoliberal, a exploração do trabalho humano, o falseamento da verdade e todo tipo de discriminação. Entretanto, não se conclua daí que Freire prioriza a função social do conhecimento em detrimento da função teórica. Ao definir o que considera ético no trabalho do educador, lembra que o problema não consiste no fato de o professor posicionar-se ou assumir seu ponto de vista. O problema está em absolutizar o seu ponto de vista, ou seja, em desconhecer que a razão ética pode não estar com ele. Por isso, considera prejudicial qualquer declaração de (pretensa) neutralidade, o que não significa, porém, abandonar uma preocupação rigorosamente ética. Para Paulo Freire, a ética do educador não pode omitir nem mentir a respeito de outros pressupostos que discordem dos próprios. Ora, aqui está o reconhecimento do comportamento de quem avoca o primado da ciência e da verdade. Sem negar a possibilidade de assumir um papel militante, estabelece os limites para tanto através de um forte mecanismo de vigilância emoldurado no marco da honestidade 
Os desafios na produção do conhecimento histórico...

que, se os juízos de valor são inerentes à função social da história, eles são estranhos à sua função teórica. Fiscalizar para evitar que o utilitarismo da história coloque em xeque a validação do seu conhecimento específico e da sua legitimidade teórica é, portanto, uma tarefa fundamental do historiador.

A ética na ciência histórica passa pelo ater-se à ciência, à verdade e ao conhecimento científico. Logo, a honestidade intelectual do historiador passa pelo não ocultamento de outras matrizes explicativas que não sejam as suas e pela explicitação dos limites e dificuldades do seu trabalho assim como das suas perspectivas teóricometodológicas.

Em relação à questão da ética, as premissas do historiador do TP e da HI não são diferentes daquelas do coletivo dos historiadores. Em todo caso, pensando nas particularidades da sua abordagem, pode-se esperar do especialista do tempo presente uma maior explicitação dos limites da sua análise, da colocação da sua perspectiva e do reconhecimento dos resultados parciais e inconclusos que produz, não temendo assumir posições desde que elas não afetem a natureza científica do seu trabalho.

Por último, deve fazer parte da ética dos historiadores o compromisso de tornar compreensível a dinâmica das sociedades desvelando o que está velado, expondo as relações concretas de dominação e de poder sobre as quais se rege a sociedade contemporânea. E, se nos casos limites, o expert deve assumir posições mais visíveis diante das iniciativas de falsificação da história, que se comporte assim em todas as situações concretas, tomando toda a cautela que lhe impõe a ética. Isso quer dizer que ele deve agir como ser social instrumentalizado para analisar seu tempo sem deixar de socializar suas informações e sem sonegar explicações. Como muito bem conclui Fontana (1998, p. 37), "Um dos grandes desafios que temos como historiadores é o de voltar a metermo-nos nos problemas do nosso tempo [...].” 


\section{Enrique Serra Padrós}

\section{The challenges of production of historical knowledge in perspective of present time}

Abstract. The article examines some issues concerning the production of historical knowledge establishing relationships with the History of the Present Time approach. The reflections about Present Time as a field of analysis of History has developed in the last years. They express: the attempt to delimit these fields of analysis and intervention of historians; the adequacy of their theoreticalmethodological apparatus and the making of new instruments which may enable them to face properly the challenge of the historical speeding up in the last decades. Keywords: Present Time. History of the Present Time. Production of Historical Knowledge.

\section{Notas}

${ }^{1}$ Sobre este ponto, entende-se aqui que é só no discurso que o historiador pode assumir uma (pretensa) postura de neutralidade, pois essa postura, no plano concreto, escamoteia a existência de tomada de posição em função de interesses definidos. O que o historiador deve almejar, sim, é a postura da isenção, ou seja, sem esconder a sua perspectiva de análise nem os elementos que a demarcam, ele pode explicitar, de forma objetiva, a sua leitura dos fatos, sempre e quando não ignore (conscientemente) ou manipule informações que possam ser desfavoráveis às premissas que pautam o seu ponto de vista.

${ }^{2}$ Avaliar o nosso próprio tempo é sempre um desafio marcado por dúvidas e receios. Dussel, Finocchio \& Gojman (1997, p. IX) temem “[...] produzir versões fragmentadas, de arrogar-nos a verdade absoluta num debate que continua aberto, em resumo, de esquecer uma parte importante da história. [...] Entretanto, queremos ressaltar que esta aproximação ao ensino da história argentina recente, certamente incompleta e suscetível de melhora, tem como propósito central ajudar a fazer memória na e desde a escola. A construção de outra relação com o passado recente, tanto dos adultos como dos jovens, é uma tarefa inadiável se queremos que o Nunca Mais tenha raízes sólidas e perduráveis na sociedade argentina”.

\section{Referências}

BARRACLOUGH, Geoffrey. Introdução à História Contemporânea. São Paulo: Círculo do Livro, s/d.

BÉDARIDA, François. Tempo presente e presença da história. In: FERREIRA, Marieta de Moraes; AMADO, Janaína (Org.). Usos e abusos da história oral. Rio de Janeiro: Fundação Getúlio Vargas, 1996.

Anos 90, Porto Alegre, v. 11, n. 19/20, p.190-223, jan./dez. 2004 


\section{Os desafios na produção do conhecimento histórico...}

BÉDARIDA, François. As responsabilidades do historiador expert. In: BOUTIER, Jean; JULIA, Dominique (Org.). Passados recompostos: campos e canteiros da história. Rio de Janeiro: Editora UFRJ; Editora FGV, 1998.

BERNSTEIN, Serge; MILZA, Pierre. Conclusão. In: CHAUVEAU, Agnès; TÉTARD, Philippe. Questões para a história do presente. Bauru, SP: EDUSC, 1999.

BOUTIER, Jean; JULIA, Dominique (Org.). Passados recompostos: campos e canteiros da história. Rio de Janeiro: Editora UFRJ; Editora FGV, 1998.

Em que pensam os historiadores. In: Passados recompostos: campos e canteiros da história. Rio de Janeiro: Editora UFRJ; Editora FGV, 1998.

BRAUNSTEIN, N. A. et al. Psicología: ideología y ciencia. México: Siglo XXI, 1979 .

CHARTIER, Roger. A visão do historiador modernista. In: FERREIRA, Marieta de Moraes; AMADO, Janaína (Org.). Usos e abusos da História Oral. Rio de Janeiro: Fundação Getúlio Vargas, 1996.

CHAUVEAU, Agnès; TÉTARD, Philippe. Questões para a história do presente. Bauru, SP: EDUSC, 1999.

CHESNEAUX, Jean. ¿Hacemos tabla rasa del pasado? Madrid: Siglo XXI, 1984.

DIAS, Reginaldo. Considerações sobre a História Imediata e o colapso do chamado Socialismo Real. Pós-História, Assis-SP, n.3, p. 57-75, 1995.

DUSSEL, Inés; FINOCCHIO, Silvia; GOJMAN, Silvia. Haciendo memoria en el país de Nunca Más. Buenos Aires: EUDEBA, 1997.

FERREIRA, Marieta de Moraes; AMADO, Janaína (Org.). Usos e abusos da História Oral. Rio de Janeiro: Fundação Getúlio Vargas, 1996.

FREIRE, Paulo. Pedagogia da autonomia: saberes necessários à prática educativa. São Paulo: Paz e Terra, 1996.

FONTANA, Josep. História: análise do passado e projeto social. Bauru, SP: EDUSC, 1998.

História depois do fim da História. Bauru, SP: EDUSC, 1998.

HOBSBAWM, Eric. Sobre História. São Paulo: Companhia das Letras, 1998.

LACOUTURE, Jean. A história Imediata. In: LE GOFF, Jacques (Org.). A História Nova. São Paulo: Martins Fontes, 1998.

LE GOFF, Jacques. Memória e História. Campinas, SP: Editora da UNICAMP, 1996.

Anos 90, Porto Alegre, v. 11, n. 19/20, p.190-223, jan./dez. 2004 


\section{Enrique Serra Padrós}

LE GOFF, Jacques. A visão dos outros: um medievalista diante do presente. In: CHAUVEAU, Agnès; TÉTARD, Philippe. Questões para a história do presente. Bauru, SP: EDUSC, 1999.

PAILLARD, Bernard. História Imediata. In: BURGUIÈRE, André. Dicionário das Ciências Históricas. Rio de Janeiro: Imago, 1993.

PEREYRA, Carlos et al. Historia ¿̇para qué? Buenos Aires: Siglo XXI, 1984.

RÉMOND, René. Algumas questões de alcance geral à guisa de introdução. In: FERREIRA, Marieta de Moraes; AMADO, Janaína. (Org.). Usos e abusos da História Oral. Rio de Janeiro: Fundação Getúlio Vargas, 1996.

RIOUX, Jean-Pierre. Pode-se fazer uma história do presente? In: CHAUVEAU, Agnés; TÉTARD, Philippe. Questões para a história do presente. Bauru, SP: EDUSC, 1999.

RODRIGUES, Gabriela; PADRÓS, Enrique Serra. História Imediata e Pensamento Único: reflexões sobre a História e o ensino de História. In: HELFER, Nadir; LENSKIJ, Tatiana. Memória e ensino de história. Santa Cruz, RS: Ed. UNISC, 1999.

VIDAL-NAQUET, Pierre. Los asesinos de la memoria. Madrid: Siglo XXI, 1994.

VILAR, Pierre. A memória viva dos historiadores. In: BOUTIER, Jean; JULIA, Dominique (Org.). Passados recompostos: campos e canteiros da história. Rio de Janeiro: Editora UFRJ; Editora FGV, 1998. Entrevista. 